\title{
ESCOLA X CULTURA: PROPOSTA DE ESCOLA PARQUE COMO UM ESTUDO DE CASO
}

\section{SCHOOL X CULTURE: PARK SCHOOL PROPOSALAS A CASE STUDY}

\author{
Larissa de Rezende ${ }^{1}$, Arq \\ Marcele Salles Martins ${ }^{2}$, Me. \\ (1) Complexo de Ensino Superior Meridional \\ e-mail: lari-medeiros@hotmail.com \\ (2) Instituto de Desenvolvimento Educacional do Alto Uruguai \\ e-mail: arqmarcelesalles@gmail.com
}

Arquitetura escolar, educação inclusiva, escola parque.

O baixo desempenho escolar da educação pública, a precariedade de espaço físico, somado a inexistência de espaços públicos qualificados, culminou na proposta de um projeto arquitetônico escolar voltado para atividades extracurriculares envolvendo a ludicidade, inclusão e capacidade cultural, com o intuito de atender crianças e adolescentes entre 6 a 15 anos.

\section{School architecture, inclusive education, park school.}

The low school performance of public education, the precariousness of physical space, added to the lack of qualified public spaces, culminated in the proposal of a school architectural project aimed at extracurricular activities involving playfulness, inclusion and cultural capacity, in order to serve children and adolescents between 6 and 15 years of age.

\section{Introdução}

O baixo desempenho da educação pública brasileira tem sido amplamente discutido pelos diversos segmentos da sociedade. Segundo notícias da imprensa, as avaliações de desempenho dos alunos promovidos pelo Ministério da Educação apontam um crescimento significativo de índices negativos [Redação Época, 2015]. No entanto, sabe-se ainda que as políticas de educação, bem como sua infraestrutura física culminaram nessa situação.

O quadro atual acaba por impactar a sociedade, tanto na vida estudantil, quanto na vida adulta. 


\section{$16^{\circ}$ \\ ERGODESIGN USIHC CINAHPA}

Ressalta-se, portanto, a carência e a urgência de melhorias no ensino público brasileiro, tanto no método de ensino quanto no ambiente construído, possibilitando a construção de cidadania e conhecimento.

Na busca de resgatar as avaliações positivas, no final da década de 1940, Anísio Teixeira fundou a escola-parque. Uma proposta de escola pública que permitisse a permanência do aluno em tempo integral, possibilitando atividades extracurriculares e acesso à cultura. Com a premissa de que a educação pudesse criar uma sociedade mais democrática e formar seres humanos livres.

Diante da problemática nacional da oferta de qualidade da educação pública, permitindo a inserção de um equipamento público urbano em comunidade carente para propiciar a geração de encontro, conhecimento, apropriação por parte da comunidade, ponto de referência, espaço de troca, segurança, culmina a proposta de implantação de escola parque. O projeto visa implementar a escola parque com base nas três ideias principais a escola como proposta de uma educação completa, princípios modernos de arquitetura e como ponto de convívio. [BASTOS, 2009].

A proposta a ser apresentada objetiva o resgate de uma comunidade carente a partir da oferta de educação de qualidade, onde o ambiente construído propicie novas experiências.

\section{Escola Parque - Rede de ensino integral no Brasil}

No inicio do século XX surge uma série de pensadores, com novas ideias e novos modelos pedagógicos. Um dos primeiros foi John Dewey (1859-1952), para o educador americano, os professores deveriam se conectar aos interesses dos alunos e tinha a premissa de uma educação na constante reconstrução de experiência em um mundo em transformação. [BASTOS, 2009]. Após Dewey, surgem diversos pensadores com conceitos inovadores para a educação, dentre eles, Rudolf Steiner (1861 - 1925), Maria Montessori (1870 1952), Lev Vygotsky (1896-1934), Jean Piaget (1896-1980), que trazem novos modelos educacionais, todos eles colocando o aluno como o $16^{\circ}$ Ergodesign - Congresso Internacional de Ergonomia e Usabilidade de Interfaces Humano Tecnológica: Produto, Informações Ambientes Construídos e Transporte

$16^{\circ}$ USIHC - Congresso Internacional de Ergonomia e Usabilidade de Interfaces Humano Computador

CINAHPA | 2017 - Congresso Internacional de Ambientes Hipermídia para Aprendizagem.

centro do processo de aprendizagem.

[KOWALTOWSKI, 2011].

A base do desenvolvimento de ensino no Brasil vem da Europa e da América do Norte, havendo segundo Kowaltowski [2011], o surgimento de diversos pensadores, tais como: Anísio Teixeira Spínola, Darcy Ribeiro e Paulo Freire.

Em 1920 no Brasil, a atenção se volta para a educação e começa a percepção de que a mesma é importante para o desenvolvimento do país. Foi nesse período que surge Anísio Teixeira (19001971) um educador que idealizou com os ensinamentos de John Dewey e William Kilpatrick a construção da pedagogia no Brasil.

[KOWALTOWSKI, 2011].

De acordo com a autora, na década de 1930, Anísio Teixeira vai para Brasília lutar pela função social da rede de ensino, o mesmo monta um grupo de reformistas e naturalistas para juntos reconstruir a pedagogia brasileira. $\mathrm{O}$ educador acreditava que escola, biblioteca e museu tinham os mesmos princípios, e deveriam caminhar juntos, para ele o ambiente escolar deveria ser o mais próximo da vida em sociedade.

Paulo Freire (1921-1997) considerado um dos grandes pedagogos do país, é respeitado por sua contribuição na educação, acreditava que a rede de ensino devia ser de âmbito popular, para todas as classes sociais, sendo construída com a ajuda da população.

Já Darcy Ribeiro (1922-1997), desenvolveu a ideia da escola de tempo integral em lugares periféricos, para que as crianças não acabassem se envolvendo no mundo do crime. Ribeiro era defensor das inovações, contribuiu para a "Marcha a Década da Educação" e foi dele que surgiu a ideia de que as crianças de 7 anos obrigatoriamente deveriam ingressar na rede de ensino.

A questão da educação integral faz parte da história de ensino no Brasil desde o movimento Escola Nova, na metade do século XX. Quem promoveu essa rede de ensino brasileira foi Anísio Teixeira, a Escola Parque seria a experiência de ensino para a educação integral do homem. [CORDEIRO, 2001].
Realização:

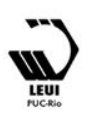




\section{$16^{\circ}$ \\ ERGODESIGN USIHC CINAHPA}

De acordo com a autora, a escola, para Anísio Teixeira, precisava:
"Educar em vez de instruir, formar homens livres em vez de homens dóceis, preparar para um futuro incerto em vez de transmitir um passado claro, ensinar a viver com mais inteligência, mais tolerância e mais felicidade. O interesse do estudante devia orientar o seu aprendizado num ambiente de liberdade e confiança mútua entre professores e alunos, em que esses fossem ensinados a pensar e julgar por si mesmos.” [BASTOS, 2009].

Com base em Bastos [2009], o projeto norteador para a concepção da escola parque, foram as escolas norte-americanas. Teixeira arquitetou um sistema que seria dirigido por "escolas-classe" e "escolas-parque" - no entorno de uma escolaparque teriam quatro escolas-classe com capacidade de mil alunos cada, onde no turno inverso ao da escola os alunos frequentariam a escola-parque, que forneceria atividades complementares tais como: educação física, social, cultural e industrial.

De acordo com Cavaliere [2010], foi em 1950 que Anísio Teixeira conseguiu concretizar suas ideias, com a criação do Centro Educacional Carneiro Ribeiro projetado pelo arquiteto Diógenes Rebouças e implantado na Bahia. O Centro era para crianças de 07 a 15 anos, tinha capacidade para quatro mil alunos, que ficavam no complexo das 7 h30 às $16 \mathrm{~h} 30$. A concretização do centro foi uma realização de toda a teoria e prática de Teixeira para a educação pública no Brasil.

\section{Procedimentos Metodológicos}

A metodologia a ser empregada nesse projeto está estruturada em quatro etapas. A primeira destinada a realização de revisão de literatura, seguida da abordagem de visita in loco e estudo de caso. A terceira engloba o diagnóstico da área de implantação a nível regional e local e a quarta etapa a proposição de anteprojeto arquitetônico.

O estudo de caso é uma pesquisa empírica que investiga um fenômeno contemporâneo dentro de seu contexto real, em que as fronteiras entre o fenômeno e o contexto não são claramente evidentes em que múltiplas fontes de evidência são $16^{\circ}$ Ergodesign - Congresso Internacional de Ergonomia e Usabilidade de Interfaces Humano Tecnológica: Produto, Informações Ambientes Construídos e Transporte

$16^{\circ}$ USIHC - Congresso Internacional de Ergonomia e Usabilidade de Interfaces Humano Computador

CINAHPA | 2017 - Congresso Internacional de Ambientes Hipermídia para Aprendizagem.

utilizadas [YIN, 2005]. Assim a essência de um estudo de caso ou a tendência de todos os tipos de estudo de caso é que tentam esclarecer uma decisão ou conjunto de decisões. Dessa maneira, esse tipo de estratégia passa a ser adequado a uma pesquisa em que procura aplicá-la num projeto.

A partir dos estudos de caso realizados e de visita in loco a escolas de ensino fundamental foi fundamentado o programa de necessidades, distribuído em setores que conformam os serviços oferecidos na escola-parque que se encontra alinhado às definições da Norma de Acessibilidade e a Lei de Diretrizes e Bases da Educação Básica.

\section{Projeto Arquitetônico}

A premissa principal para o desenvolvimento do anteprojeto arquitetônico surge da valorização humana, tendo como objetivo principal qualificar o ensino e a infraestrutura do entorno, integrando espaços de lazer, educação e cultura em um único lugar, possibilitando a integração das pessoas do bairro e dos alunos da escola. O projeto desenvolvido procurou atender, também, a base das ideias de Bastos (2009), que menciona para o projeto de uma escola parque é necessário ser desenvolvido como proposta de uma educação completa, ser um ponto de convívio da comunidade e possuir princípios modernos de arquitetura.

A área de implantação da escola se insere em um dos bairros mais carentes da cidade, próximo de uma região com ocupações irregulares, ao longo da ferrovia, visualizada na Figura 1. 


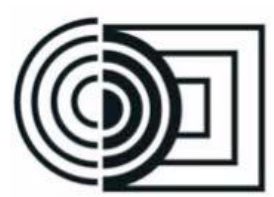
CINAHPA

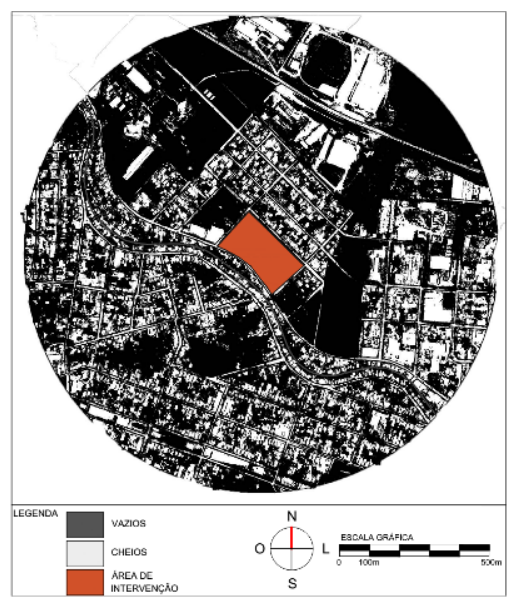

Figura 1 - Mapa Nolli.

A intenção projetual foi criar uma escola dividida em blocos, que permitisse o uso público do espaço, privatizando apenas o bloco educacional de ensino.

Como conceito formal a edificação prima pela relação da proposta para as pessoas, relacionando seus elementos a nível dos olhos. A implantação incorpora formas lineares interligadas por caminhos suavemente orgânicos que irão trazer traços da via férrea.

O entorno da área de implantação segue predominantemente altura de um e dois pavimentos (Figura 2), a proposta foi manter alturas de no máximo dois pavimentos, tornando, assim, um ambiente convidativo e com uma demarcação de acesso marcante, tendo em vista que será aberto para a população.

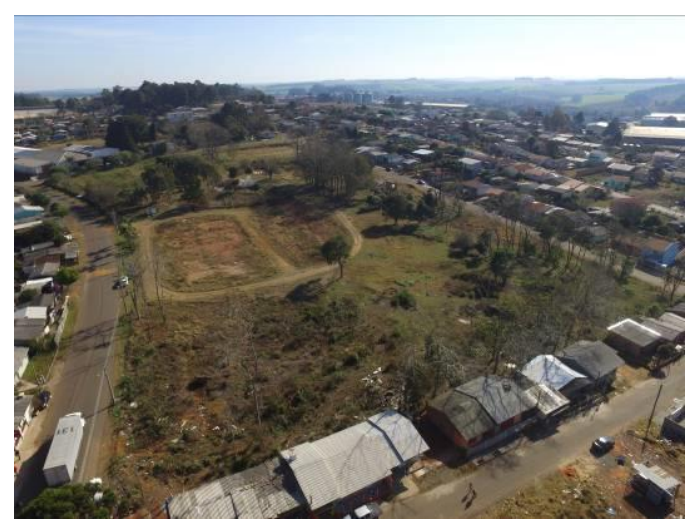

Figura 2 - Vista aérea da área de implantação.

Para a concepção da proposta foram utilizados eixos norteadores para a divisão da área de $16^{\circ}$ Ergodesign - Congresso Internacional de Ergonomia e Usabilidade de Interfaces Humano Tecnológica: Produto, Informações Ambientes Construídos e Transporte

$16^{\circ}$ USIHC - Congresso Internacional de Ergonomia e Usabilidade de Interfaces Humano Computador

CINAHPA | 2017 - Congresso Internacional de Ambientes Hipermídia para Aprendizagem.

implantação. A área foi dividida por dois eixos imaginários, de ambos os sentidos do terreno (Figura 3) [REIS, 2002]. De um lado foram dispostas as atividades educacionais, com acessos individualizados para público, professores, estudantes e serviço. De outro, a área de lazer para a comunidade, denominado parque.

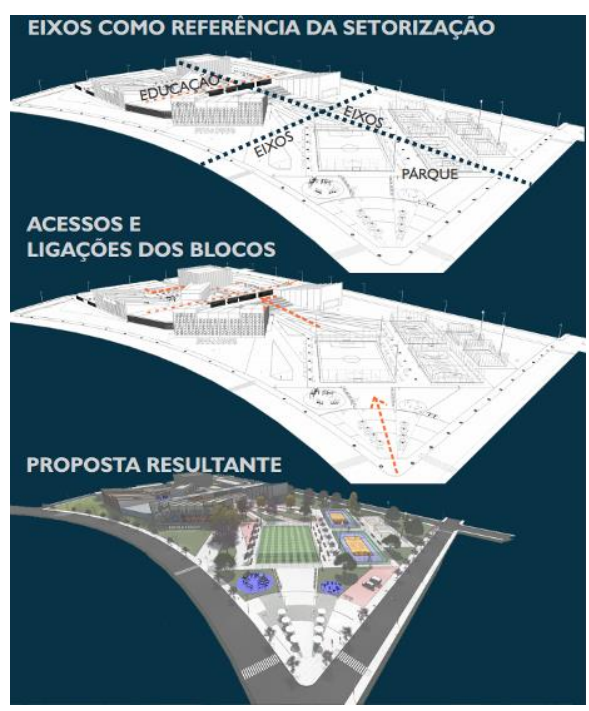

Figura 3 - Eixos norteadores.

O parque possui duas funções: uma destinada ao lazer, com quadras esportivas (poliesportiva, areia, campo de futebol), com bancos próximos aos mesmos e com árvores implantadas entre eles para impedir a incidência de radiação direta nas pessoas. A outra função destinada a espaços de contemplação, anfiteatro, praça de alimentação, espaço para food truck, mobiliário urbano. permitindo o uso público pela população em todos os horários (Figura 4). Um percurso de ciclovia e caminhada inclui toda a extensão do terreno, como pode-se observar na Figura 5.

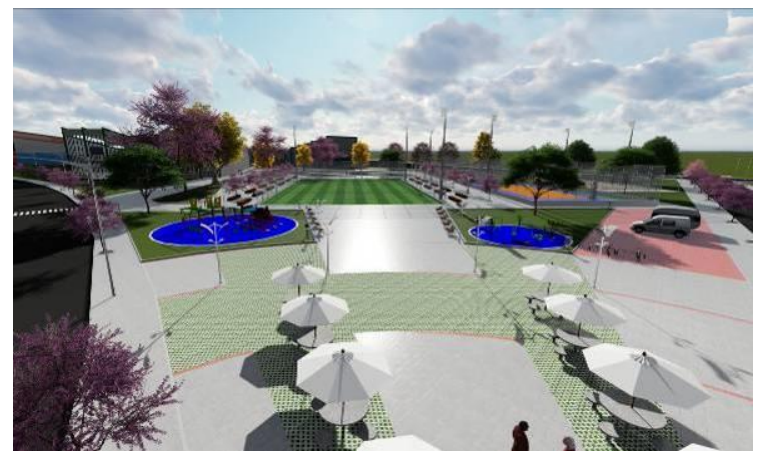

Realização:

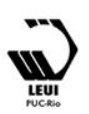

UNIVERSIDADE FEDERAL DE SANTA CATARINA 


\section{$16^{\circ}$ \\ ERGODESIGN USIHC CINAHPA}

$16^{\circ}$ Ergodesign - Congresso Internacional de Ergonomia e Usabilidade de Interfaces Humano Tecnológica: Produto, Informações Ambientes Construídos e Transporte

$16^{\circ}$ USIHC - Congresso Internacional de Ergonomia e Usabilidade de Interfaces Humano Computador

CINAHPA | 2017 - Congresso Internacional de Ambientes Hipermídia para Aprendizagem.

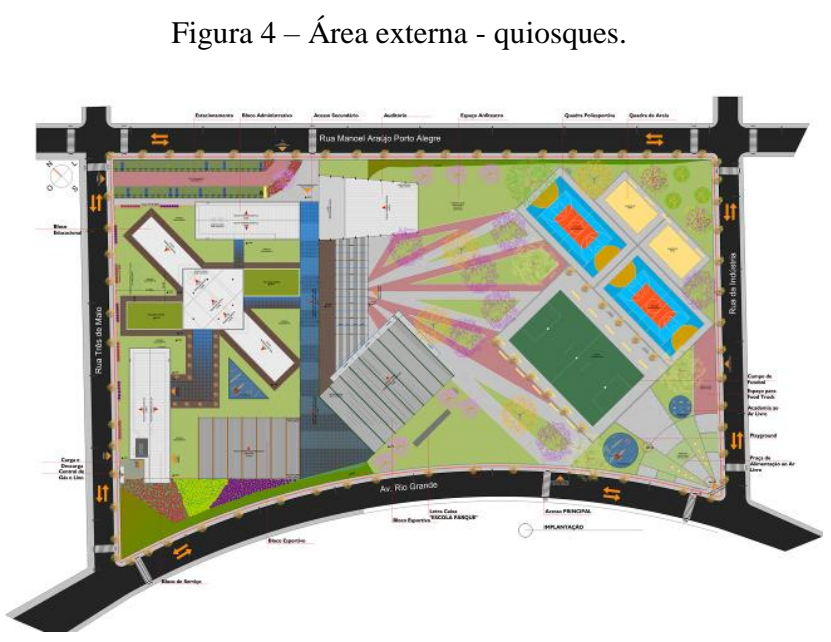

Figura 5 - Implantação geral.

A camada destinada à educação foi setorizada permitindo que os espaços internos obtivessem melhor aproveitamento de luz natural e ventilação, além de possibilitar a separação hierárquica dos acessos, mantendo-os distintos, propostos em consonância aos parâmetros de projeto escolar [KOWALTOWSKI, 2011]. A escolha da localização do setor educacional, também, foi influenciada pela cota do terreno, no nível elevado, fazendo uma relação subjetiva com o conhecimento, de que o mesmo deve ser priorizado.

O projeto arquitetônico contempla 5 blocos: serviço, administrativo, educacional, esportivo e auditório (Figura 6). O auditório possui 207 lugares e destina-se a atividades da escola e pode ser usado pela comunidade para eventos culturais e ao ar livre.

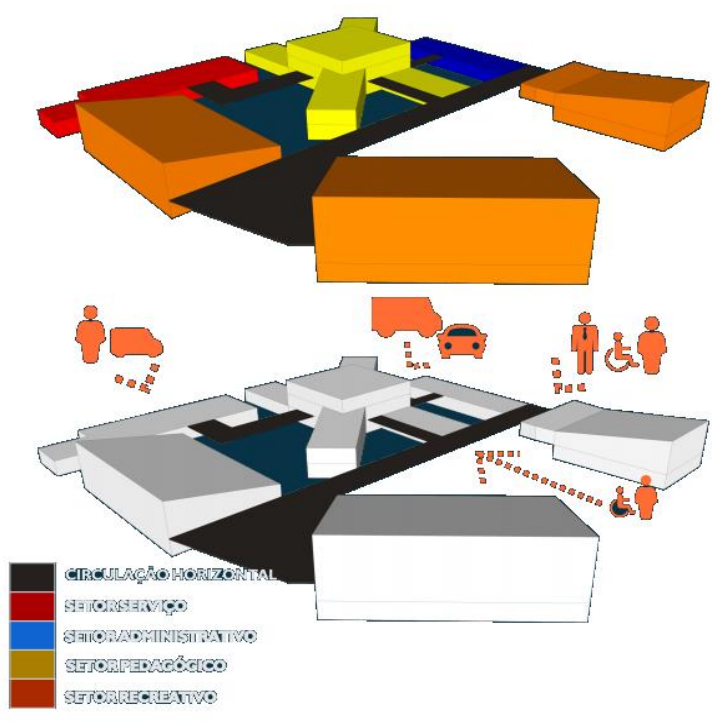

Figura 6 - Setorização da proposta.

A escola possui um programa de necessidades amplo e com inúmeras possibilidades de layout, com o objetivo de mudar os conceitos de educação rígida e repetitiva que predomina hoje nas escolas públicas do país.

O projeto propõe um perfil diversificado de atividades, que se conformaram em um complexo arquitetônico (Figura 7a e 7b), atendendo pessoas de todas as faixas etárias em integração num único espaço, totalmente conectado à realidade urbana $\mathrm{e}$ social, valorizando a comunidade no desenvolvimento da sua conscientização social.

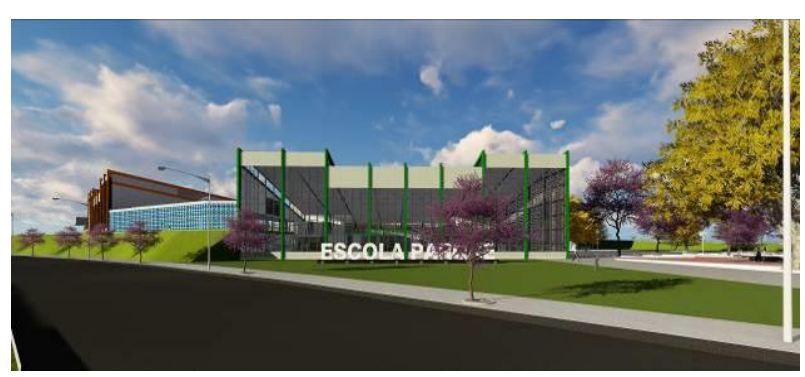

Figura 7a - Vista do complexo.
Realização:

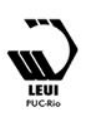



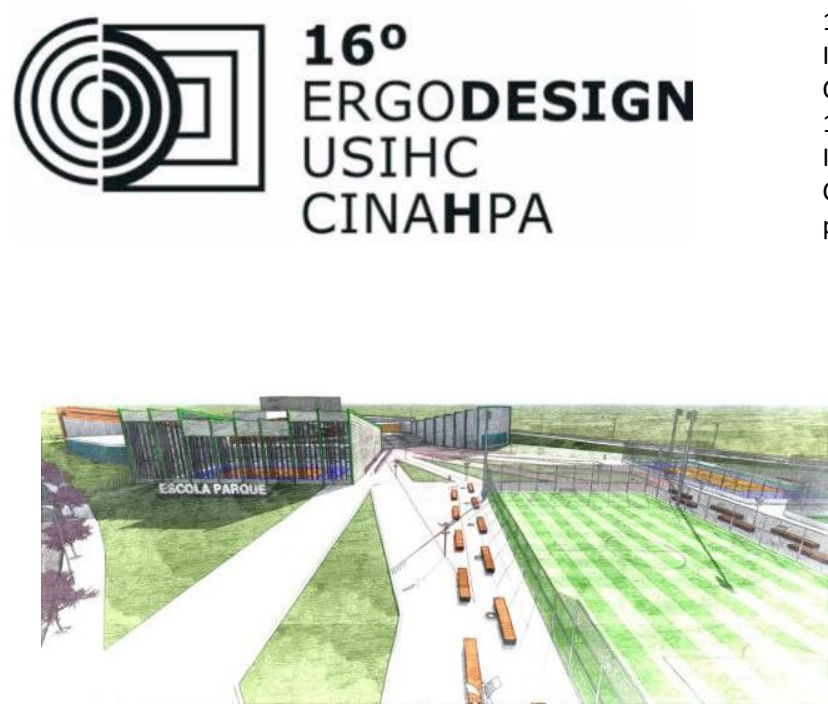

Figura $7 b$ - Vista do complexo.

O projeto do bloco educacional conta com três pavimentos, sendo o primeiro pavimento destinado a 11 salas de aula, com diferentes disposições de layout, para abrigar as séries iniciais e finais do ensino fundamental, conjunto de sanitários, átrio com circulação vertical e espaço de convivência (Figura 8). No segundo pavimento contempla salas multiuso, laboratórios de informática, ciências e artes. O terceiro pavimento é destinado a biblioteca.

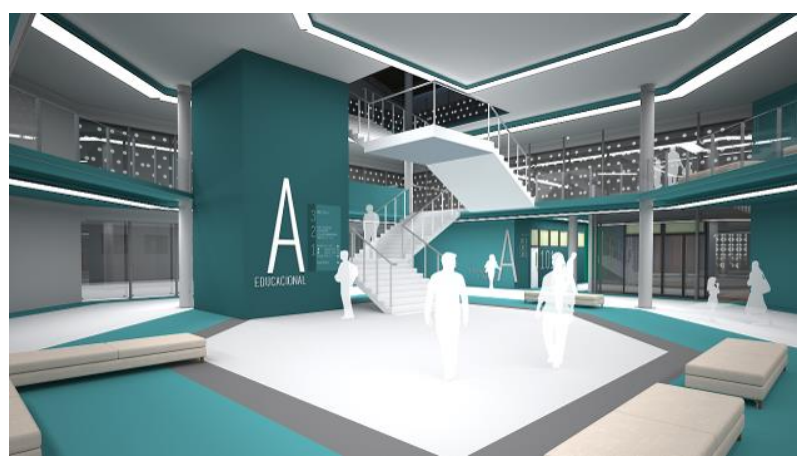

Figura 8 - Espaço de convivência.

O bloco do serviço possui um pavimento, contempla as atividades de depósitos, cozinha, vestiários e refeitório, possui acesso e estacionamento exclusivo.

$\mathrm{O}$ administrativo possui um pavimento, destinado as salas de direção, coordenação, professores, secretaria, sala de atendimento pedagógico, sanitários. Conta com estacionamento para 50 vagas, as quais são compartilhadas com o auditório.

O bloco recreativo se divide em dois: piscina semiolímpica e quadra poliesportiva, ambos com arquibancada, sanitários e vestiários. O edifício $16^{\circ}$ Ergodesign - Congresso Internacional de Ergonomia e Usabilidade de Interfaces Humano Tecnológica: Produto, Informações Ambientes Construídos e Transporte

$16^{\circ}$ USIHC - Congresso Internacional de Ergonomia e Usabilidade de Interfaces Humano Computador

CINAHPA | 2017 - Congresso Internacional de Ambientes Hipermídia para Aprendizagem. conta com grandes caixilhos de alumínio e vidro, brises verticais para controle solar nas fachadas que não estão para a coordenada sul. (Figura 9)

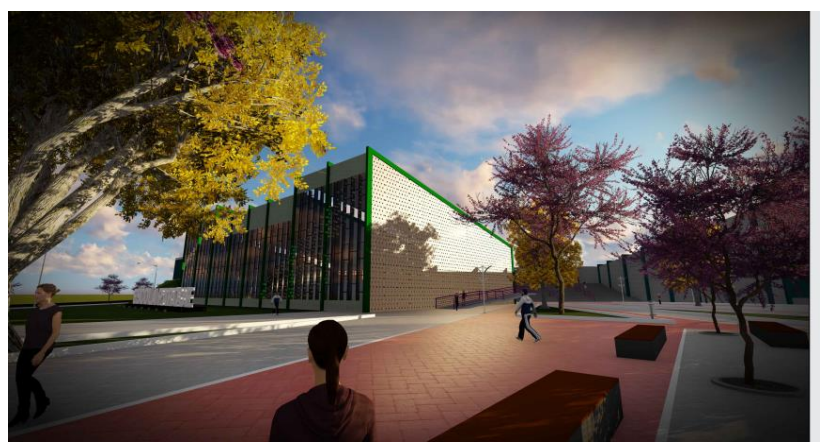

Figura 9 - Bloco Recreativo.

As técnicas construtivas utilizadas para fechamento das paredes externas são placas cimentícias, por possuírem uma prática e rápida montagem, proporcionando também conforto e resistência.

Nos ambientes internos foram utilizadas o sistema de paredes multidirecionais, que é um material que permite inúmeras possibilidades de layout (Figura 10). O sistema estrutural é o metálico por praticidade e maior flexibilidade projetual.
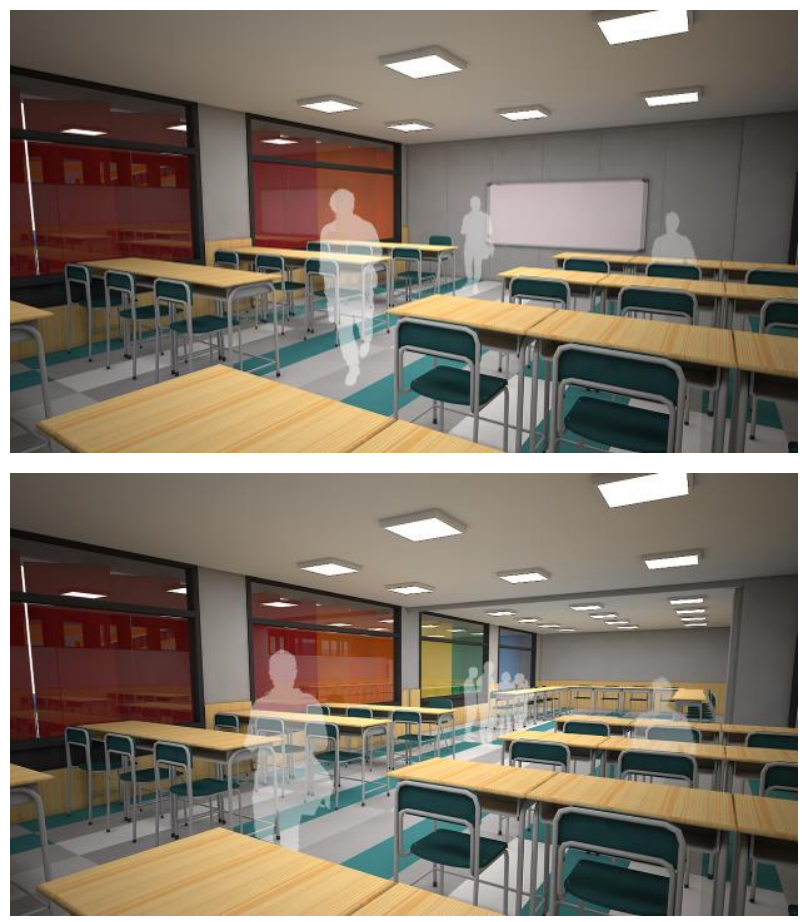

Realização:

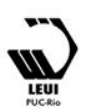

UNIVERSIDADE FEDERAL DE SANTA CATARINA
INSTITUTO FEDERAL

Santa Catarina

Câmpus Palhoça Bilíngue 
$16^{\circ}$ Ergodesign - Congresso Internacional de Ergonomia e Usabilidade de Interfaces Humano Tecnológica: Produto, Informações Ambientes Construídos e Transporte

$16^{\circ}$ USIHC - Congresso Internacional de Ergonomia e Usabilidade de Interfaces Humano Computador

CINAHPA | 2017 - Congresso Internacional de Ambientes Hipermídia para Aprendizagem.
Figura 10 - Sala de aula com o uso de parede multidirecional.

No bloco educacional, todo o edifício possui aberturas, para que possua ventilação cruzada e também possui brises metálicos (Figura 11) para controlar a incidência solar do prédio, evitando a utilização de ventilação mecânica no bloco.

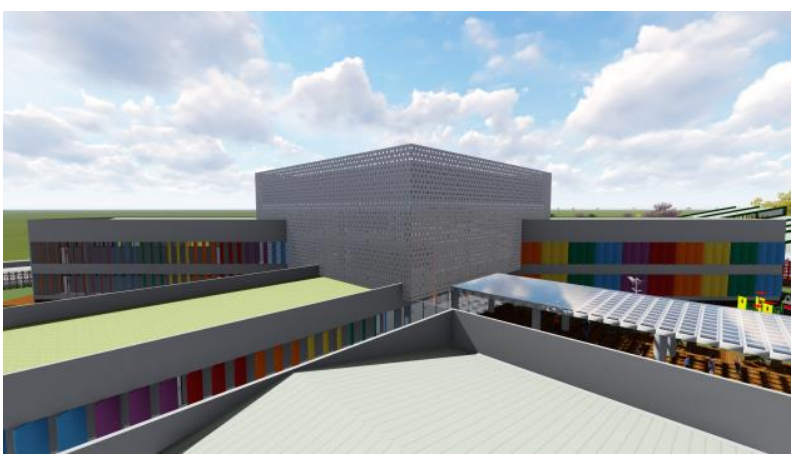

Figura 11 - Bloco Educacional.

\section{Considerações Finais}

Por meio deste estudo foi possível evidenciar que a oferta de escolas é insuficiente, a infraestrutura se apresenta deficitária na maioria das cidades e, ainda é causa de exclusão social. Para que esta realidade melhore se fazem necessárias proposições que promovam a autonomia e capacitação educacional, profissional, recreativa e social, principalmente das crianças e adolescentes a quem se destina, visando uma conscientização de toda a sociedade, que se deve investir na educação e na qualidade destes espaços.

A premissa principal deste projeto foi a valorização humana, de modo a construir uma escola de período integral para crianças e adolescentes, e um ponto de convívio para a comunidade.

A integração proposta da escola e comunidade visa qualificar o modo de vida destas pessoas invisíveis, que vivem em um entorno precário de espaço público e sem um complexo de educação adequado.

Com esta visão, a arquitetura se mostra como uma solução eficaz, no momento em que alia responsabilidade social, no desenvolvimento do ambiente construído, apresentando medidas concretas no atendimento de crianças e adolescentes em vulnerabilidade social, propondo espaços que possibilitem saúde física e psicológica, educação, autonomia e integração como um todo.

\section{Referências Bibliográficas}

BASTOS, Maria Alice Junqueira. A Escola Parque: ou o sonho de uma educação completa (em edifícios modernos). AU. Arquitetura e Urbanismo, v. 178, p. 42-45, 2009. Disponível em: $<$ http://au.pini.com.br/arquiteturaurbanismo/178/artigo122877-3.aspx>. Acesso em 27 de março de 2016.

CAVALIERE, Ana Maria. Anísio Teixeira e a Educação Integral. Paidéia (Ribeirão Preto).2010. Disponível em:

<http://www.scielo.br/scielo.php?script=sci_arttext \&pid=S0103863X2010000200012 >. Acesso em 27 de março de 2016.

\section{CORDEIRO, Célia Maria Ferreira. Anísio}

Teixeira, Uma "visão" do futuro. Estud. Av., São Paulo, v. 15, n. 42, p. 241-258, 2001. Disponível em:

$<\mathrm{http} / / / \mathrm{www}$.scielo.br/scielo.php?script=sci_arttext \&pid=S010340142001000200012\&lng=en\&nrm=i so>. Acesso em 27 de março de 2016.

KOWALTOWSKI, D. C. Arquitetura Escolar: o projeto do ambiente de ensino. São Paulo: Oficina de Textos, 2011.

REDAÇÃO ÉPOCA. O Ensino Público no Brasil: Ruim, Desigual, Estagnado. 2015. Disponível em: $<$

http://epoca.globo.com/ideias/noticia/2015/01/boensino-publico-no-brasilb-ruim-desigual-eestagnado.html >. Acesso em: 27 de março de 2016.

REIS, Antonio T. Repertório, análise e síntese: uma introdução ao projeto arquitetônico. Porto Alegre, Ed. Da UFRGS, 2002.

YIN, R. K.Estudo de caso: planejamento e métodos. $3^{\mathrm{a}}$ ed. Porto Alegre: Bookman, 2005. 